\title{
Study of Construction of Network English Teaching Platform Based on Multimedia
}

\author{
https://doi.org/10.3991/ijet.v12i02.6154 \\ Qian Zhang \\ Luoyang Institute of Science and Technology, Luoyang, China \\ zqly1983@163.com
}

\begin{abstract}
In order to adapt to the needs of the rapid development of social networks, how to effectively improve college students' English comprehensive application ability, and rapidly improve listening and speaking skills has become an important research goal of college English teaching. This paper describes the main problems to be solved, and makes full use of the network and multimedia technology to build an open, interactive network English teaching platform. The platform provides students with abundant videos, images, voices, texts and other resources, so that the students can get help from teachers and other partners to improve their English ability.
\end{abstract}

Keywords-Multimedia, Teaching Platform, English learning

\section{Introduction}

Digital network and information technology has an increasing influence in the society, and how to utilize the network to study better has become a crucial problem which various colleges and universities have to face. Undoubtedly, the characteristics of the network technology era are the most prominent feature of the 21 st century, and the more extensive application in the network is very popular in colleges and universities. Now there are numerous teaching and learning platforms on the internet and the websites of some universities. It can be predicted that the online teaching and learning model can make education more fair and effective in the long run. It can narrow the knowledge gap among different regions and offer more opportunities for people to enrich themselves. There are some good examples, like MOOCs (Massive Open Online Courses) which provides free classes from some top universities and institutions. Some universities even offer academic credits to students who take certain courses [1]. Another prominent website, Khan Academy, provides free classes in math, art, computer programming, economics, physics, chemistry, biology, medicine, finance, history, etc.

Teaching and learning language online enjoys exceptional advantages. In traditional classes, teachers need to create the tasks and language atmosphere for students. Even though teachers may use multimedia devices to assist, he or she is the only resource. However, with the help of computer simulating technology, computers can imitate real situations. Students can immerse themselves, learn from it, talk to real 
people and even get some feedback, such as the feedback of the problems of the pronunciation, and grammar errors in the conversation or composition. There are vast amounts of resources on the internet ranging from literature to astronomy, not to mention language materials, all of which can make classes more diversified. The significance of this research is giving some implications to the establishment and perfection of the college English teaching mode in Luoyang. It is a change from the old English teaching mode.

\section{$2 \quad$ Literature Review}

The English teaching platform in the network environment is not only software, but also a teaching means and teaching tools. Therefore, the design of the platform must not only conform to the user, but also consider the needs of the students from the angle of teaching itself. In the industrial era, standardization of teaching was a sign of progress. But at the same time, it was not able to fully consider the diversity of students' personalities, the life goals of students and the different needs of society. What society demands now are creative talents, and the cultivation of them is on the premise of education. Therefore, the challenge of an information society for education is comprehensive and profound. The knowledge economy is motivated and driven by human's creativity, so the universities and schools should be able to cultivate the students' creativity and flexibility by utilizing various teaching methods [2].

For the various teaching methods, there are concepts about online language teaching and learning environments, such as distance education, CALL (computer-assisted language learning), network-based language teaching, etc. Computer-assisted language learning concentrates on the aid of a computer. Computer-assisted language learning is defined as the search for and study of applications of the computer in language teaching and learning [3]. Feng Hui considered computer-assisted language learning as an approach to language teaching and learning in which computer technology is used as an aid to presentation, reinforcement and assessment of materials to be learned, usually including a substantial interactive element [4]. Hongling Zhang also proposed a hypothesis about normalizing online foreign language learning and conducted some experiments [5].

\subsection{The Network teaching platform}

The network teaching platform is the product of computer technology development. It can be considered as an online teaching support platform which is based on the Internet. It also has materials contents for personal learning. Furthermore, the network teaching platform can make the study of English easier and more convenient. So a definition can be defined as a high technology systems-combined intelligence platform which can assist teaching and make personal study easier and more convenient.

In the learning platform, various pieces of content are selected from textbooks, papers, TV shows, etc. The resource platform contains more English learning material 
than the learning platform. The management platform facilitates teachers to manage students' learning process. The test platform provides the automatic and fast online test-paper making, online text answering and automatic modifying. In preparing the platform, teachers can choose teaching materials according to the needs of their class at the center of the teaching platform.

Overall, teachers can manage teaching, editing, course ware, online examination, examination and approval work, organize online feedback according to usual scores, statistics about students' learning situation, etc. through the network teaching platform. Furthermore, the network teaching platform which has abundant learning materials is a powerful learning tool for personal learning. Students can read the materials, arrange learning plans, check the material contents, update homework, collaborate learning with classmates, exchange ideas with teachers, view the academic record and participate in the school community communication, etc. The teaching platform will become a bridge of communication between teachers and students.

\subsection{Analysis of the needs for the English teaching platform}

As is known to all, network English learning environment is totally different form the traditional English learning environment. Network English learning environment refers to the application of the modern media such as the multimedia and network to collect, transform, and share the related teaching information via tests, picture, video, audio etc [6]. Therefore, students can learn English in a natural and relaxing environment. So compared with the traditional English learning environment, network English learning environment is helpful for building student-centered rather than teachercentered learning environment. Besides, students can learn whenever and wherever they want while teachers play a guiding role to provide the related learning content, different ways of practice and so on[7]. At the same time, teachers can get the students' responding in time and analyze it through the learning system.

The English teaching platform should include the following modules. The first one is the teaching resources where students can get abundant resources and download them. They should also learn to manage the teaching resources, such as exercise, audio, video, special training and testing. It is free for them to upload, download, modify and delete them. The second one is teaching and learning. When students enter the English network teaching platform, the corresponding segment of the navigation links will appear and they can independently browse their course information and other relevant knowledge. The third one is the tests and analysis. Test is the key part on the whole English teaching platform. According to students' learning habits, the different tests will be arranged in a week. After the test, both students and teachers can check the results of the test after they log in and analysis of the whole class tests will be done by the platform automatically. The last module is about question and answer. Network English teaching Platform can help students solve some problems they encounter during the learning process. In the whole process, students can make communication between teachers and the questions they ask will be answered immediately. So the platform provides a new way for students to ask questions and teachers 
to answer questions [8]. Only in this way can it reflect the instant function of the platform, convenient for both students and teachers.

\subsection{Design of the English teaching platform based on multimedia}

As is shown in Figure 1, in this system, the following parts are determined: teaching resources management (management and maintenance of the resources from teachers), practice management (online publishing and management of the practice by teachers), performance management (teachers' management of students' practice and self-rated performance), question answering (answering the questions from students), online learning (students' learning of the teaching resources provided by teachers), online test (students' self testing), user management (administrators to manage teachers and students users), rights management and so on.

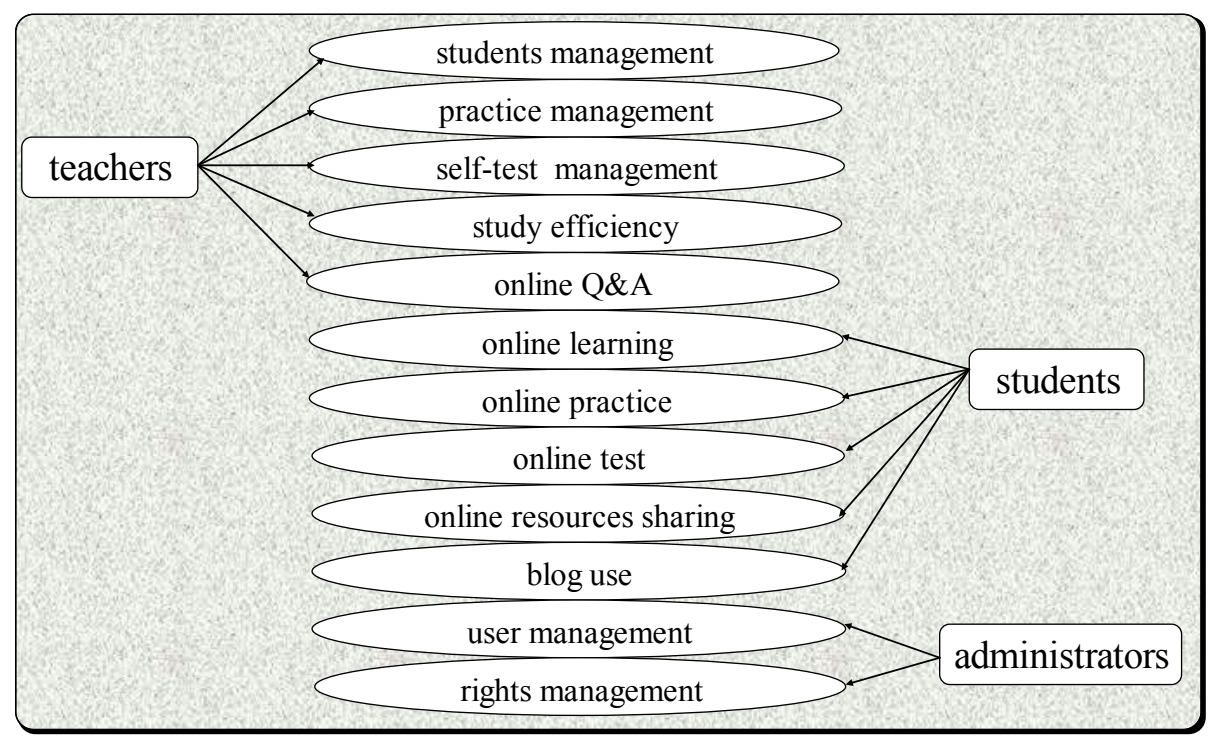

Fig. 1. Platform Requirement Modeling

\section{$3 \quad$ Research Design}

A research project is designed to investigate the construction of a network English teaching platform based on multimedia. It includes the research questions, research subjects, research instruments and research procedures.

\subsection{Research questions}

Based on a brief review of the relevant studies, this study intends to answer the following research questions: 
1. What are the teachers' and student's attitudes to the network teaching platform?

2. What are the teacher's and student's practices in the network teaching platform?

3. What are the attractive parts of the online course to the users? What functions do they think can be added to the platform?

4. What are the impacts of the teaching platform on English teaching and learning?

\subsection{Research subjects}

The investigation was carried out in Luoyang Institute of Science and Technology. The subjects were all freshmen with non-English majors. They were selected from four classes, 30 students in each class on average, and altogether 120 students. They were respectively called Class 1,2,3,4. The students from these four classes have no significant difference in English level proficiency. The students from Classes 1 and 2 were taught by the same teacher A while Classes 3 and 4 were instructed by another teacher B. Classes 1 and 2 were regarded as the experimental group (EG) and Classes 3 and 4 as the contrast group (CG). Teacher A integrated the platform to conduct teaching while teacher $\mathrm{B}$ adopted the traditional teaching method. Meanwhile, to guarantee the validity of the study, they used the same syllabus, teaching plans and textbook. The two teachers were female and their age, education, professional titles and teaching years are very similar.

\subsection{Research instruments}

The instruments employed in the present study involved questionnaire, test and interview.

Since questionnaire is an effective way of gathering information of the study, it is suitable for this research.

In order to check its effectiveness, 2 tests were conducted during the experiment. The pretest was held at the beginning of the second term, the post-test was held at the end of the second term.

In order to achieve the goal of understanding more about teaching and learning effect of network platform, interviews were also carried out to get more specific information about the use of network platform for English language teaching,which was the necessary supplement for the questionnaire and would be of great help in explaining the results of the whole study.

\subsection{Research procedures}

On December 15, 2015, at the end of the first term, 120 questionnaires were distributed to the students of EG. 117 responses were available and three questionnaires were invalid due to missing information or inappropriate answers.

The responses were anonymous and confidential, and SPSS 19.0 was used as a data analysis device, by which statistical description can be finished. The interviews were conducted two weeks later, including 15 students and they were randomly chosen. 
In the meanwhile, the test was performed during this period. On April 10, 2016, at the beginning of the second term, both groups were given the first comprehensive test as the pre-test, and on June 26, 2016, the final exam was held as the post-test. The data from the pre-test and post-test were analyzed by SPSS 19.0.

\section{$4 \quad$ Results and Discussions}

\subsection{Data analysis and discussion based on the questionnaire}

This section deals with the quantitative analysis based on the data collected in this survey. The results of the questionnaire study are obtained by using SPSS 19.0 analysis and will be discussed in detail as follows.

Item 1: Do you like surfing the Internet?

When asked this question, 64\% students claimed that they enjoy going online very much and 31\% students insisted that they had some interest in the web. Only 5\% students said they did not like online surfing. The result is shown in Figure 2.

The result shows that most of the students like Internet and it is one of the basic network learning. It means that they will surf on Internet if they are in need.

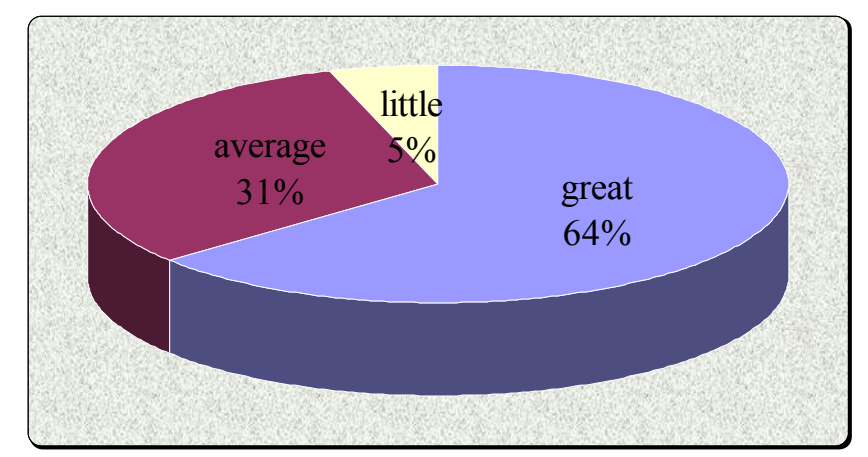

Fig. 2. Whether the students like internet

Item 2: Where do you go online when you are on campus?

When asked this question, 49\% students preferred personal computers and only $23 \%$ students chose computer classroom on campus and another $28 \%$ students said that they accessed the Internet in other places. The figure shows that many students have to go on Internet by using their own PCs, which reflects the number of computers of Luoyang Institute of Science and Technology is not sufficient to meet students' needs. The result is shown in Figure 3. 


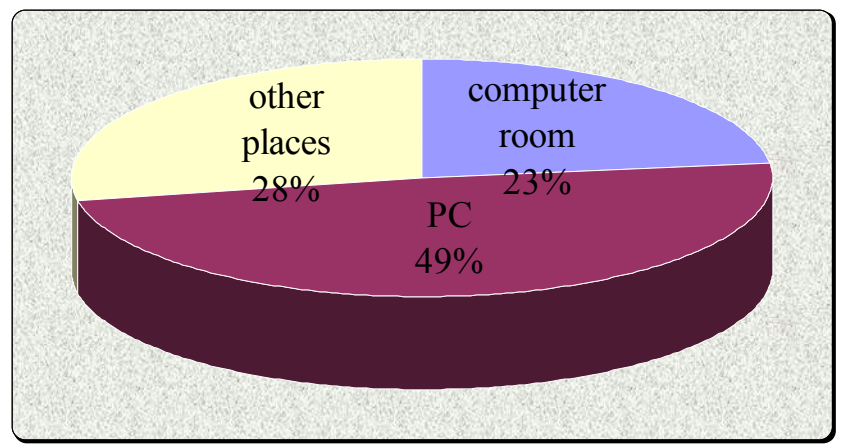

Fig. 3. the places of going online

Item 3: What is your main purpose for being on the web?

When the subjects were asked this question, $11 \%$ expressed that they used the Internet mainly for studying and $56 \%$ said that they browsed the web to find some useful information and materials. Another 33\% admitted that they accessed the net only for entertainment and fun. The figure shows that only few students can utilize the network to study and most students believe the Internet is useful and helpful to gain knowledge but they do not know the best way to do this. Therefore, it is necessary to give them some related instructions and guidance. The result is shown in Figure 4.

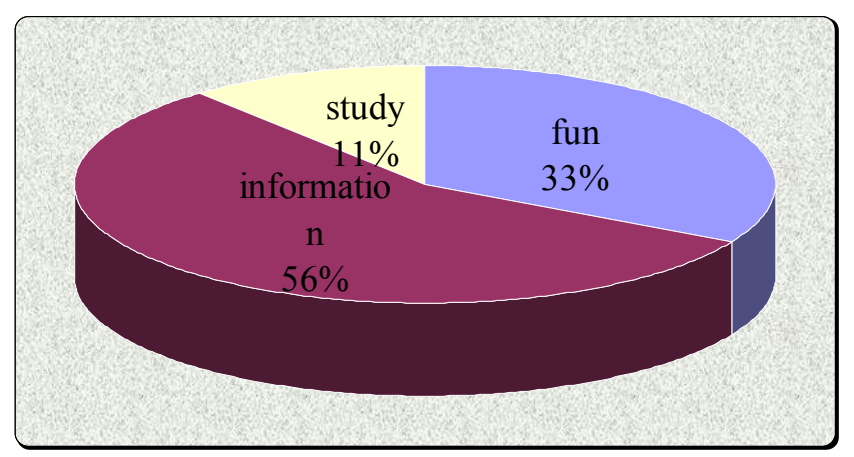

Fig. 4. The purpose of going online

Item 4: How much do you know about computers and the Internet?

When being asked this question, $15 \%$ of students declared that they had good computer skills and they were familiar with the computer operation. $80 \%$ students answered that their computer levels are average and only knew some basic knowledge of operation of computer. Only 5\% students admitted that they knew little about computers. The result shows that the majority of the students have abilities in English if they have needs and opportunities. The result is shown to use network to learn in Figure 5. 


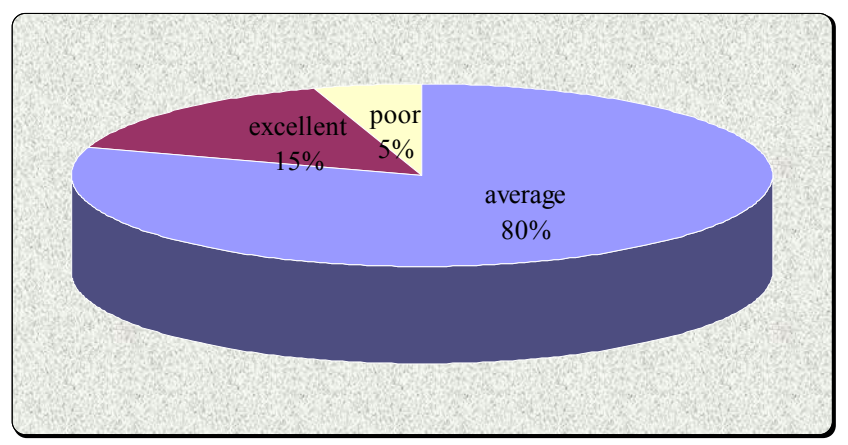

Fig. 5. The degree of knowing about network

Item 5: Do you often study English via network teaching platform?

When the subjects were asked this question, $16 \%$ said they spent much time on English on the Internet and $61 \%$ said that they occasionally studied English via a teaching platform. Another $23 \%$ answered that they never or occasionally learn English on a platform. The result displays that most students, to some extent, can apply the platform to their English learning as an assisted media. The result is shown in Figure 6.

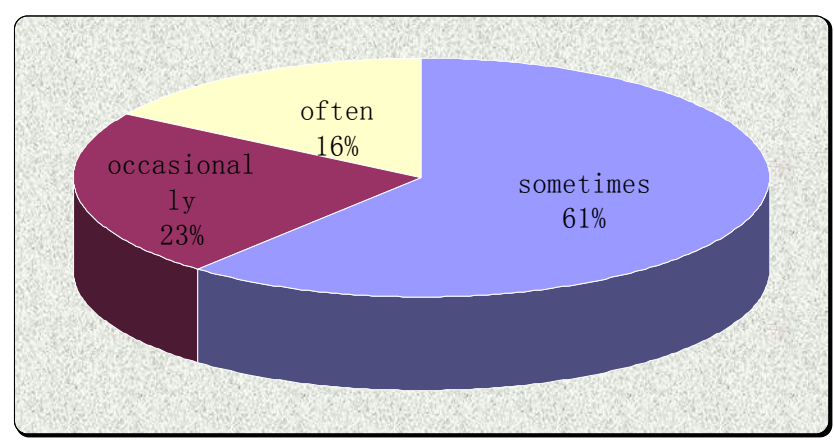

Fig. 6. Learning English on teaching platform

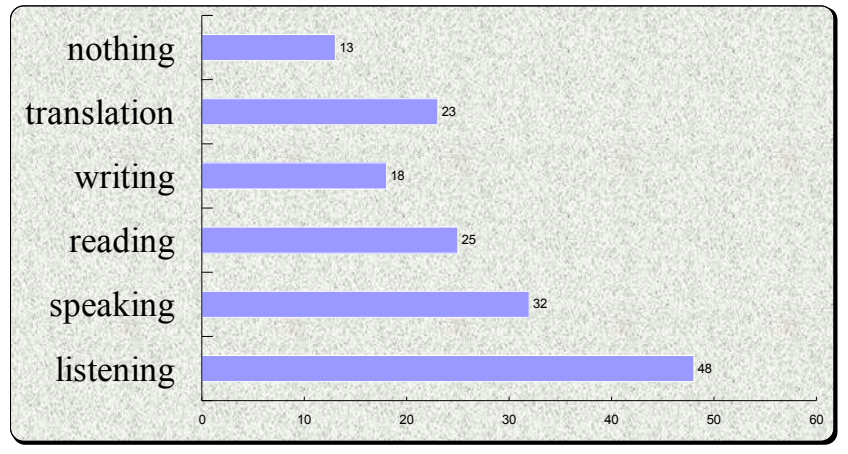

Fig. 7. The improvement of English skills 
Item 6: In which aspect do you think you get promoted most?

Among the students surveyed, $48 \%$ think that listening is promoted on the teaching platform, which ranks first in terms of various English skills.32\% think that speaking is improved, which is the second while only $18 \%$ believe that it can help develop the writing skills. Furthermore, $13 \%$ hold the view that it cannot offer any help. So, in the future, teachers should pay more attention to the design of each module as well as the diversity and practicality of materials.

The impact of teaching platform has on English learning.

Item7: I spend more time on English learning than before on the teaching platform and I can study in the places I prefer.

Item8: I will browse the web to learn something about teaching contents and textbook material posted on the teaching platform so that I can better understand what I have learned in class.

Item9: I am more actively involved in classroom activities and an offered more opportunities for interaction in class after e-learning on the teaching platform.

Item10: I prefer to perform my assignment on the teaching platform and I can do a better job.

According to the Table 1, as to Item 7, it is inferred that the teaching platform can enhance students' initiative for learning and their study time for English, since it is more convenient and not limited by time and place. So we can see that one of the benefits of the teaching platform is that it can enlarge the class capacity and increase the teaching efficiency. Moreover, the responses to Items 8, 9, 10 indicate that the teaching platform is beneficial to language learning and it can be used as a supplement and extension of classroom teaching. They believe that they can review what they have learned in class on the teaching platform and play it again and again to learn study what they feel is not yet clear until they understand. Meanwhile, most subjects agree that the learning materials on teaching platform should be constantly updated so that the students can keep up with the course.

Item 11: I often use network teaching platform.

According to Table 2, Item 11 means the value is 3.1321. While its Std. Deviations is 0.8374 . That means most of the students are in the same situation. As the table shows, $41.0 \%$ participants choose "sometimes agree" and 51.0\% participants choose "agree". This means that students are interested in network teaching platform. Item12: Do you think your university should invest more on improving the platform? Item13: Do you want to get some academic credits from some courses on the online educational platforms?

According to Tables 3 and 4, it can easily be found that the majority of students are looking forward to having high quality online educational platforms in their universities, and they also want to get some academic credits from the online courses.

In students' opinions, the teaching platform is important to college English teaching and it has good effect for their English learning. Furthermore, they would like to use the network teaching platform, if it has good effect for their English learning, and they propose some suggestions for network teaching platform. That means they consider the teaching platform in their daily life. That is to say, students would like to use the teaching platform very much. 
Table 1. Descriptive statistics for learning from the textbook.

\begin{tabular}{|l|c|c|c|c|c|c|}
\hline & $\mathbf{N}$ & Range & Min & Max & Mean & $\begin{array}{c}\text { Standard } \\
\text { Deviation }\end{array}$ \\
\hline Item 7 & 60 & 4 & 1 & 5 & 3.8125 & 0.9562 \\
\hline Item8 & 60 & 4 & 1 & 5 & 3.7956 & 0.9658 \\
\hline Item9 & 60 & 4 & 1 & 5 & 3.6015 & 1.0569 \\
\hline Item10 & 60 & 4 & 1 & 5 & 3.4621 & 1.1321 \\
\hline
\end{tabular}

Table 2. I often use network teaching platform

\begin{tabular}{|c|c|c|c|c|c|c|}
\hline $\begin{array}{c}\text { Totally } \\
\text { Disagree }\end{array}$ & $\begin{array}{c}\text { Almost } \\
\text { Disagree }\end{array}$ & $\begin{array}{c}\text { Sometimes } \\
\text { Agree }\end{array}$ & Almost Agree & Totally Agree & Mean & $\begin{array}{c}\text { Standard } \\
\text { Deviation }\end{array}$ \\
\hline $3.0 \%$ & $1.2 \%$ & $41.0 \%$ & $51.0 \%$ & $1.8 \%$ & 3.1321 & 0.8374 \\
\hline
\end{tabular}

Table 3. More investment on improving the platform

\begin{tabular}{|l|c|}
\hline Do you think your university should invest more on improving the platform? & number \\
\hline A. Yes, I think they should. & 24 \\
\hline B. To some extent, I think they should & 48 \\
\hline C. To some extent, I don't think they should & 2 \\
\hline D. No, I don't think they should. & 5 \\
\hline E. I don't know & 11 \\
\hline
\end{tabular}

Table 4. More academic credits from teaching platforms

\begin{tabular}{|l|c|}
\hline \multicolumn{1}{|c|}{$\begin{array}{c}\text { Do you want to get some academic credits from some courses on the online } \\
\text { educational platforms? }\end{array}$} & number \\
\hline A. Yes, I do. & 38 \\
\hline B. To some extent, I do. & 48 \\
\hline C. To some extent, I don't. & 3 \\
\hline D. No, I don't. & 7 \\
\hline E. I don't know. & 4 \\
\hline
\end{tabular}

\subsection{Data analysis and discussion based on the test}

We use SPSS 19.0 to analyze the data from the test and it is described as follows:

As is shown in Table 5, the average score of EG is 54.253 while that of the contrast is 54.865. The standard deviation is 13.281 and 11.946 respectively. This shows that there is no significant difference between the two groups $(P=0.1518>0.05)$. Even the average score of EG is slightly lower than that of CG.

As Table 6 shows the average score of EG is 64.753 while that of the CG is 58.165. The standard deviation is 10.586 and 11.446 respectively. The result indicates that their English has owed both in EG and CG after a period of study. It also can be deduced that the difference between the two groups is remarkable $(P=0.000<0.01)$. That is, the grades of EG is clearly better than that of CG. Therefore, it can be concluded that the network teaching platform helps enhance the students' English results. 
Table 5. The result of pretest

\begin{tabular}{|l|l|c|c|c|}
\hline \multicolumn{1}{|c|}{ GROUP } & N & MEAN & STD.DEVIATION & P \\
\cline { 1 - 4 } EG & 60 & 54.253 & 13.281 & \multirow{2}{*}{0.1518} \\
\hline CG & 60 & 54.865 & 11.946 & \\
\hline
\end{tabular}

Table 6. The result of post-test

\begin{tabular}{|l|c|c|c|c|}
\hline \multicolumn{1}{|c|}{ GROUP } & N & MEAN & STD.DEVIATION & P \\
\cline { 1 - 4 } EG & 60 & 64.753 & 10.586 & \multirow{2}{*}{0.000} \\
\hline CG & 60 & 58.165 & 11.446 & \\
\hline
\end{tabular}

\subsection{Discussion about interview}

Interviews with some open questions are helpful in explaining the result of the investigation and can be viewed as an important supplement to the questionnaire. The interview was carried out in a week after the questionnaires were performed. $15 \mathrm{stu}$ dents and 3 teachers took part in the interview. They gave their opinions about the above questions.

Most of the students held the view that the biggest obstacles that affect their using teaching platform is the poor network situation. They complained that the number of computers is inadequate and the majority of the computers are older that cannot meet the needs of the learner. So they expect that the hardware facilities and the network environments will be improved soon. In addition, some students believe that the materials are not attractive enough or disordered so that the students feel bewildered. Meanwhile, they feel that the activities on the platform are not well designed and organized, which has a great influence on teacher-student interaction and students' motivation. Finally, they think they are lacking in the attitude and ability of autonomous learning so that they hope the teacher can offer some help and instructions in this aspect. Most of the teachers propose that the old machine and slow net speed always make them feel upset and frustrated., which declined their interest in teaching platform. Therefore, it is essential to update the equipment and develop the network environment. Moreover, some teachers feel that their computer skills are not excellent enough,to carry out network teaching, so it is suggested that some necessary and effective training should be provided.

\section{Conclusions}

The development of English teaching platforms is an irresistible trend. There have been many extraordinary platforms in some famous universities. They have many similar functions but also some unique innovations accordingly. By analyzing some creative and personalized functions of the English teaching platforms according to the results of the survey and interview, the author knew that students have their personal needs of foreign language learning. Students may be attracted by different functions of the platforms, which may improve their learning interests and learning skills. In the 
days to come, English teaching platform based on campus network may play more and more important roles in the university education. The new learning model changes students' learning style and pace, which will bring new challenges even revolution to the education system. In order to face the challenge or revolution, there must be sophisticated planning before the construction of high quality courses. Building a platform needs a lot of time and money, so it is also necessary to share the teaching and learning resources with other universities or to cooperate with some commercial online English teaching platforms to avoid redundant construction. The history of online educational platforms is relatively short. Most universities haven't been able to use them in a large scale especially in compulsory courses. In order to make the research more convincing and representative, it is necessary to carry out long-term case study of learners and contrastive analysis of different educational platforms, such as teaching the same course in traditional classes and on educational platform to see the difference in effects and students' attitude or doing the same experiment on different online educational platforms. Although the experiment is difficult to conduct, for there are many variables like the degree of familiarity of students and teachers, and the way the course organized, it can be of great practical significance.

\section{References}

[1] Zuoli Wang, "MOOC: a storm is coming?" China Network Education. 2013, vol.12, no.4, pp. 11-14.

[2] Wan Alwi S.R., Manan Z.A., Chezghani M., "A graphical method for simultaneous targeting and design of multiple utility systems". Chemical Engineering Transactions, 2014, vol.12, no.39, 1045-1050.

[3] Bradley P, "Invasion of the MOOCs, Community Colleges Seek Best of Both Worlds in Embrace of Internet-based Course", Community College Week, 2012, vol.24, no. 10, pp. 6-7.

[4] Hui Feng, "The Role of Teachers in Computer Assisted Foreign Language Teaching", Media in Foreign Language Instruction, 2012, vol.12, no.12, pp.34-38.

[5] Hongling, Zhang, 2010, "Normal Computer Aided Foreign Language Teaching: Problems and Solutions", Media in Foreign Language Instruction, 2010, vol.12, no.10, pp.105-110.

[6] Ying Luo, Liang Tan, "The Rate of Return on E-learning Investment in Higher Education", Academic Forum , 2010,vol.24, no.22, 22-26.

[7] Shieh, D, "These Lectures Are Gone in 60 Seconds", The Chronicle of Higher Education, 2009, vol.12, no. 26, pp.23-26.

[8] Carmen De Pablos Heredero, Sajid Haider, Antón García Martinez. "Relational Coordination as an Indicator of Teamwork Quality: Potential Application to the Success of eLearning at Universities". International Journal of Emerging technologies in learning, 2014, vol.9, no.5, pp. 67-70.

[9] Jamieson J, "Trends in Computer-based Second Language Assessment", Annual Review of Applied Linguistics, 2005, vol. 24, no.25, pp.228-242. https://doi.org/10.1017/s0267 190505000127

[10] Jiao Xuhua, Chen Cheng, "Thoughts on Application of Multimedia in Education, Proceedings of the 2011 International Conference on Future Computer Science and Education", ICFCSE, 2011,vol. 1, no.1, pp.591-594. 
[11] Lingfang Fu, Jianding Yang, "Teaching and Learning Model Based on Multimedia and Network", Foreign Languages and Their Teaching, 2007, vol. 12, no.10, pp. 36-38.

[12] Yang Xiaohui, "Status quo and Future: Multimedia Application in Higher Education", Advanced Materials Research, 2010, vol.12, no. 22, pp. 1023-1027. https://doi.org/10.4028/www.scientific.net/AMR.121-122.1023

\section{$7 \quad$ Author}

Qian Zhang is a lecturer in School of Foreign Languages, Luoyang Institute of Science and Technology, Luoyang, 471023, China. Her research interests include the applied linguistics, English language teaching, etc. (email:zqly1983 @163.com)

This work was supported by Fund program: Soft Science Program of Science and Technology Agency in Henan province (142400411422). Article submitted 17 August 2016. Published as resubmitted by the authors 20 December 2016 